\title{
La traducción al latín de algunos términos griegos y su repercusión en los comentarios a los Aphthonii Progymnasmata ${ }^{1}$
}

\author{
Trinidad Arcos PEREIRA \\ María Dolores GARCía DE PASO \\ Universidad de Las Palmas de Gran Canaria \\ Instituto Universitario de Análisis y Aplicaciones Textuales (IATEXT) \\ trinidad.arcospereira@ulpgc.es \\ mdoloresgarciadepaso@ulpgc.es
}

Recibido: 9 de junio de 2015

Aceptado: 30 de septiembre de 2015

\section{RESUMEN}

En este trabajo hemos examinado comentarios a la traducción al latín del ejercicio de la Fábula de los Progymnasmata de Aftonio para ver cómo afecta la traducción de algunos términos al comentario. Dado que, al traducir de una lengua a otra, difícilmente hay correspondencia exacta, el traductor opta por la solución que estima más adecuada, primando ciertos matices sobre otros y, con frecuencia, llega, incluso, a dotar al término de acepciones en la lengua meta que no existían en la lengua origen. La elección realizada no parece obedecer a otra razón que a preferencias del traductor, pero tiene consecuencias e influye en los comentaristas. Por otra parte, la existencia de un término acuñado no impide que tanto los traductores como los escoliastas creen otros nuevos, tal vez por deseo de mostrar originalidad. Finalmente, la traducción tiene una doble vertiente: de un lado, influye en el entendimiento del concepto y en el comentario, y, de otro, refleja la concepción que de la realidad tiene el traductor.

Palabras clave: Progymnasmata. Fábula. Traducción del griego al latín. Aphthonius. Alardus Aemstelredamus. Reinhardus Lorichius Hadamarius. Juan de Mal Lara.

Arcos Pereira, T. - García De Paso, Ma D., «La traducción al latín de algunos términos griegos y su repercusión en los comentarios a los Aphthonii Progymnasmata», Cuad. Fil. Clás. Estud. Lat. 35.2 (2015) 319-336.

The impact of some greek translated terms into Latin on the commentaries on Aphthonii Progymnasmata

\footnotetext{
ABSTRACT

In this work, we have analysed commentaries to the Latin translation of the exercise of the fable of Aphthonius' Progymnasmata in order to check how the translation of some terms may affect the com-

${ }^{1}$ Este trabajo se ha realizado en el marco de los Proyectos de Investigación FFI2011-24959 y FFI20453859-P, financiados por el Ministerio de Economía y Competitividad.
} 
mentary. Since in the process of translation from one language into another it is very difficult to find exact equivalence, the translator makes the choice he considers most adequate, giving priority to some semantic nuances over other ones, and, sometimes, he even provides the term in the target language with meanings that were not present in the source language. This choice seems to respond only to the translator's preferences but it has consequences and it influences on the commentators. Moreover, the previous existence of an already coined term does not prevent translators and scholiasts from creating new ones, maybe eager to be original. Finally, the effect of translation is twofold: on the one hand, it affects the way the concept is understood and the commentary, and, on the other hand, it reflects the translator's view of reality.

Keywords: Progymnasmata. Fable. Translation from Greek to Latin. Aphthonius. Alardus Aemstelredamus. Reinhardus Lorichius Hadamarius. Juan de Mal Lara.

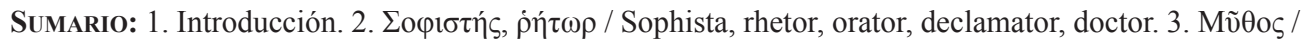

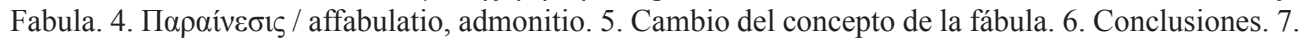
Referencias bibliográficas. 7.1. Textos. 7.2. Diccionarios y léxicos. 7.3. Artículos y monografías.

\section{INTRODUCCIÓN}

Los Progymnasmata son manuales de ejercicios, creados por los profesores de retórica griegos para que, con ellos, los estudiantes aprendieran a escribir y a hablar. Los más conocidos son los de Teón, Hermógenes y Aftonio ${ }^{2}$. Los de Hermógenes fueron trasmitidos por Prisciano en versión latina (Prisciani Caesariensis Praexercitamina $^{3}$ ) y, de este modo, fueron conocidos durante la Antigüedad tardía y la Edad Media en occidente 4 . Otra fue la suerte que corrieron los manuales de Teón y Aftonio que no se recuperaron hasta mucho después, hasta la caída de Bizancio. Aftonio se editó antes que Teón ${ }^{5}$, la primera edición en griego es de Aldo Manucio de 1508, pero no sólo se editó en griego, sino que también se hicieron traducciones al latín, lengua más accesible, y se acompañaron, en ocasiones, de comentarios ${ }^{6}$. La traducción al latín realizada por Rodolfo Agrícola es la primera en el tiempo, aunque no se editó hasta 1532, mucho después de la muerte del humanista, acaecida en 1485, y llegó a la imprenta gracias a Alardo de Ámsterdam que la editó de nuevo, pero acompañada de un comentario en 1539. Previamente, Cataneo había publicado en Bolonia en 1507 su traducción al latín. Por otro lado, muchos humanistas no se conformaron con

2 M. Patillon ha publicado una edición crítica de los tres rétores griegos en dos volúmenes en Les Belles Lettres: Patillon-Bolognesi (1997) y Patillon (2008). Sobre los progymnasmata, véase Pérez (2003 ${ }^{1}$ ), Arcos (2015), Arcos - García de Paso (en prensa).

${ }^{3}$ Keil incluye los Praexercitamina en sus Grammatici Latini (Keil-Hertz, 1981, pp.430-440). Posteriormente, Passalacqua ha publicado una nueva edición de los ejercicios para la que ha consultado los numerosos códices que han transmitido el texto (1987). Sobre la tradición manuscrita de Prisciano, puede verse el trabajo de la misma autora (1978).

4 Sobre la presencia de Teón en España, véase Pérez (2013).

5 Angelo Barbato publica la editio princeps de Teón en Roma, en 1520. La primera traducción al latín la publica J. Camerario en 1541 en Basilea.

${ }^{6}$ Sobre las versiones latinas pueden consultarse los trabajos de Clark (1952), Margolin (1979) y de Green-Murphy (2006). 
utilizar los progymnasmata ya existentes y escribieron unos propios ${ }^{7}$, inspirados en los anteriores.

En este artículo nos proponemos mostrar que la traducción no es intrascendente, sino que son muchas las posibilidades al alcance del traductor y que la elección puede llegar incluso a condicionar el comentario. Para ello, vamos a centrarnos en tres comentarios y en el ejercicio de la fabula.

Alardo de Amsterdam ${ }^{8}$, Reinhard Lorich ${ }^{9}$ y Juan de Mal Lara ${ }^{10}$ enriquecieron los ejercicios de Aftonio en versión latina con unos comentarios ${ }^{11}$. Alardo y Mal Lara utilizaron la traducción de Rodolfo Agrícola y Lorich una mixta, mezcla de la de Cataneo y la de Agrícola. Alardo editó en 1539, en Colonia, los trabajos de Agrícola en dos volúmenes con el título de Rodolphi Agricolae Phrisii Lucubrationes aliquot lectu dignissimae... Uno de ellos está dedicado a su De inuentione rhetorica y el otro a la traducción de los Progymnasmata de Aftonio, a la edición de los Praexercitamenta de Prisciano y a sus comentarios a Declamationes de Séneca, además de Orationes, Epistulae, algunas traducciones de autores como Isócrates o Platón, y poemas. Alardo añade unos scholia suyos tanto a los Progymnasmata de Aftonio como a los Praexercitamenta de Prisciano, así como a algunos de los otros trabajos de Agrícola. Lorich editó por primera vez unos comentarios a los Progymnasmata de Aftonio so-

\footnotetext{
${ }^{7}$ Hemos consultado los de Pedro Mosellano (1530); Antonio Lullio (1551); Alfonso de Torres (Pérez $2003^{1}$ ), cuya primera edición es de 1569; Pedro Juan Núñez (Nunnesius, 1596), publicado por primera vez en sus Institutiones Rhetoricarum libri quinque en 1578, en Barcelona; Bartolomé Bravo, (1589); Francisco Pomey (1664); Bartolomé de Alcázar (1688), publicado en su De ratione dicendi, en sus ediciones de 1681 y 1688. Tampoco faltan Progymnasmata en lengua vernácula como los de Palmireno (1573).

${ }^{8}$ Alardo, sacerdote católico y editor de Rodolfo Agrícola, nació en 1491 en Ámsterdam y murió el 28 de agosto de 1544 en Lovaina. Fue durante su niñez alumno de Willem Hermanz Goudanus y, más tarde, dio clases en Alkmaar, uno de los grandes centros humanísticos de la época de Holanda. Al mismo tiempo que Alardo enseñaban en Alkmaar Rescius y Murmellius, y estudiaba Nannius, quien terminaría siendo rector de ese mismo centro. Después, Alardo marchó a Lovaina en donde trabajó como corrector para el impresor Thierry Martens. Allí conoció a humanistas como Erasmo. Su vida transcurre entre Lovaina, Colonia y Amsterdam, sin olvidar sus estancias en el monasterio de Egmond, en donde ejercía como abad su pariente, Meinard Man. Sobre la vida y obra de este autor, véase Graaf (1958).

${ }^{9}$ Reinhard Lorich (Reinhardus Lorichius Hadamarius), profesor de retórica nacido en Hadamar (Hesse), en Marburgo. Fue pastor protestante en Bernach. En 1542, se imprimió una edición suya con un comentario de los Progymnasmata de Aftonio que acompañaban a una traducción partim Agricola, partim Catanaeo. En 1546 se reeditó en Frankfurt con un prefacio del autor y esta última edición será la que se imprimirá numerosísimas veces en toda Europa durante el siglo siguiente. Véanse Johnson (1942-43, pp.436-437); Clark (1952); Margolín (1979); Rodríguez-García de Paso (2008); Cuyás (2014).

10 Juan de Mal Lara es un humanista sevillano, amigo del Brocense. Nació sobre 1524 y murió en 1571. Estudió en Salamanca y en Barcelona con Escobar como maestro. Escribió unos comentarios a los Progymnasmata de Aftonio y una Syntaxis, publicados ambos en 1567 pocos años antes de su muerte. Sobre la vida y obra de Juan de Mal Lara, véase Escobar (2000; 2004; 2012); Merino (2002); Arcos - Cuyás (2007; 2008; 2009; 2010).

${ }^{11}$ En este trabajo hemos utilizado la edición de los progymnasmata de Alardo publicada en Colonia en 1539, Rodolphi Agricolae Lucubrationes... per Alardum Aemstelredamum emendata, et additis scholiis illustrata (Alardus, 1539¹); la de Lorich de Marburgo, de 1542, Aphthonii Sophistae Progymnasmata, partim a Rodolpho Agricola, partim a Ioanne Maria Catanaeo... simul ac scholiis luculentis nouisque compluribus exemplis illustrata, per Reinhardum Lorichium Hadamarium (Lorichius, 1542) y la de Mal Lara, publicada en Sevilla, en 1567, Ioannis Mallarae in Aphthonii Progymnasmata Scholia (Mal Lara, 1567).
} 
bre una versión mixta partim Agricola, partim Cataneo $^{12}$ en 1542 en Marburgo. Mal Lara editó sus comentarios en 1567 en Sevilla, sirviéndose, como ya hemos dicho, de la versión de Agrícola.

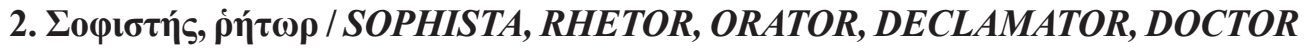

En las obras de los tres comentaristas podemos ver que se denomina sofista a Aftonio $^{13}$. En la versión de Agrícola de 1539 editada por Alardo con escolios encontramos, al comienzo de los ejercicios, antes de la fábula, un título: Aphthonii sophistae progymnasmata Rodolpho Agricola Phrisio interprete. La edición de Lorich de 1542 se titula Aphthonii sophistae progymnasmata, partim a Rodolpho Agricola, partim a Ioanne Maria Catanaeo latinitate quondam donata: iam recens longe tersius edita, simul ac scholiis luculentis, nouisque compluribus exemplis illustrata per Reinhardum Lorichium Hadamarium, pero, en cambio, al comenzar con los ejercicios, antes de la fabula, aparece Aphthonii declamatoris Praexercitamenta. La obra de Mal Lara se titula Ioannnis Mallara in Aphthonii Progymnasmata scholia, sin ningún calificativo para Aftonio, pero, tras los prolegomena, al principio del comentario que va precedido de la traducción de Agrícola, puede verse un nuevo título: Scholia in Aphthonii sophistae progymnasmata Rodolpho Agricola Phrisio interprete.

Tanto Alardo como Mal Lara se ocupan del término sophista. Alardo, en el ejercicio dedicado a la fabula, tras la traducción de Agrícola, comenta la palabra incluyendo un fragmento de De finibus de Cicerón en el que el arpinate, utilizando este vocablo, señala que Gorgias fue el primer sofista que se atrevió a hablar sobre cualquier tema que se le propusiera ${ }^{14}$; añade también otro fragmento del comentario de Agrícola al prólogo de las Declamationes de Séneca ${ }^{15}$ en el que distinguía sophista, el que enseña, de rhetor, el que se ocupa de causas en el foro, como había señalado Juan Doxopatros ${ }^{16}$, e indicaba que en latín deberían haberse traducido como doctor

\footnotetext{
12 Parece ser que, previamente, había editado en Marburgo en 1537, utilizando la versión de Agrícola, unos brevísimos comentarios a esta obra (Johnson 1942-43, pp.427-444 y Cuyás 2014, pp.153-177).

${ }^{13}$ La mayor parte de los manuscritos de Aftonio incluyen en el título el término sofista y no rhetor, como puede verse en el aparato crítico del título de sus Progymnasmata en M. Patillon (2008, p.112).

${ }^{14}$ Eorum erat iste mos qui tum sophistae nominabantur, quorum e numero primus est ausus Leontinus Gorgias in conuentu poscere quaestionem, id est iubere dicere, qua de re quis uellet audire (CIC.Fin.2.1).

${ }^{15}$ Rhetor dicitur Graece, quod Latine orator, qui causas in foro agit. Qui docet, autem Graece Sophistes uocatur, quod nos possumus interpretari doctorem: apud Latinos uero fere obtinuit consuetudo ut Rhetor, qui docet, Orator, qui dicit, uocaretur (Alardus $1539^{2}$, p.104).

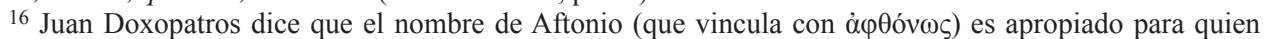

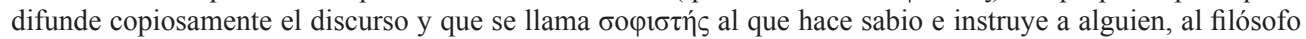
enamorado del bien, de la razón y la verdad, también al que disfraza y altera la verdad, y a quien practica temas ficticios, y $\dot{\eta} \eta \omega \rho$ es el que defiende casos en un tribunal como Demóstenes. Considera que el apelativo бофıбти́ৎ se aplica a Aftonio por su papel de instructor de retórica, porque escribió discursos ficticios o porque no actuó ante tribunales (Patillon 2008, p.50, n.3).
} 
y orator $^{17}$ respectivamente, pero que se impuso la costumbre de llamar al maestro de retórica rhetor; Alardo sigue en su comentario, por lo general, estas pautas ${ }^{18} \mathrm{y}$ raramente utiliza rhetor por orador ${ }^{19}$, aunque ese es el vocablo que prefirió Agrícola. Mal Lara, por su parte, en sus Prolegomena señala, comentando el apelativo sophista atribuido a Aftonio, que se entiende por tal el que propone imitaciones de modo ingenioso y que también es declamator; más tarde indica además que sophista es el maestro de retórica ${ }^{20}$; por otro lado, señala que rhetor es el que enseña a hablar, pero que después pasó a denominarse así al orator que, según había indicado, era el nombre que recibía el que defendía causas en el foro.

Lorich no comenta estos términos, pero, como hemos visto, la traducción partim, partim utiliza en el título de la obra la palabra sophista, Aphthonii sophistae progymnasmata, y al comienzo de los ejercicios declamator, Aphthonii declamatoris Praexercitamenta.

Así pues, para nombrar al maestro de retórica, se pueden emplear en latín muchos términos, algunos tomados del griego como sophista y rhetor, otros del propio latín, como doctor y declamator. Si examinamos estos vocablos, concluimos que sophista lo podríamos relacionar con бoфó $\zeta^{21}$, es decir, 'inteligente', 'sabio', 'sutil', 'ingenioso', pues tenemos mismo lexema y un sufijo derivativo. El significado de бoфıбти́s es, primero ‘experto', 'sabio’y, más tarde, 'profesor de Retórica'22. El vocablo $\dot{\eta} \eta \tau \omega \rho$ se emplea en griego con las acepciones de 'orador' y de 'maestro de retórica'23.

\footnotetext{
${ }^{17}$ Sobre la utilización de estos términos, véase J. Lorenzo (2009).

18 Por ejemplo utiliza rhetor por maestro: Qui apud grammaticos ea percepissent quae praexercitamenta uocabantur ... tum ad rhetoris scholam adducebantur proponebanturque eis themata qualia in libris declamationum Senecae descripta sunt ...(Alardus $1539^{1}$, p.1) y orator por orador cuando indica que sirve para atraer la atención y mitigar el hastío: quin oratores harum usu et leuant fastidium et attentionem conciliant nonnunquam (Alardus $1539^{1}$, p.2).

${ }^{19}$ Sí lo hace en el comentario a a rhetoribus usurpata, como veremos más adelante.

${ }^{20}$ Adde quod sophistae nomen Aphthonio non ab re impositum in arte rhetorica magistrum significat, quod proponat ea quae imitari debeamus, sic enim oratorem rhetoremque distinguunt periti, ut orator sit, qui ueras causas agit, sophista, qui cauillatorio modo proponit imitationes, idemque est declamator .... Rhetor uero, qui artem oratoriam docet atque idem postea etiam sit orator ac quia olim rhetores hi et sophistae in pretio erant autori nostro ab officio nomen remansit, ut Libanio, ut Theoni, qui progymnasmata conscripsere ... Eadem est proportio sophistae ad declamatorem, quae rhetoris ad oratorem (Mal Lara 1567, f.3r.).

${ }^{21}$ Según el Dictionnaire Grec-Français de Bailly (1963), бoфó es «1. prudente, sage; 2. savant, instruit; 3. ingénieux, fin, rusé». Según A Greek-English Lexicon de Lidell-Scott-Jones, es «clever in practical matters, wise, prudent; learned, wise; subtle, ingenious».

${ }^{22}$ Según el diccionario de Bailly es «habile; philosophe, sage; maitre de philosophie et d'éloquence, sophiste». Para Lidell-Scott-Jones significa: «1. master of one's craft, adept, expert, 2. wise, prudent or

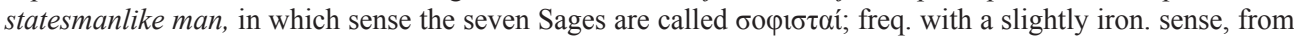
late v B.C., a Sophist, i.e. one who gave lessons in grammar, rhetoric, politics, mathematics, for money, such as Prodicus, Gorgias, Protagoras; but sts. even of Socrates (though he did not teach for money), 2. sophist (in bad

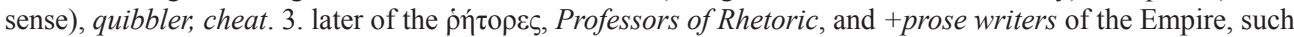
as Philostratus and Libanius».

${ }^{23}$ Para Bailly, significa «1. orateur 2. maitre d'éloquence, rhéteur 3. celui qui prononce une sentence, juge». Según Lidell-Scott-Jones: «1. public speaker 2. one who gives sentence, judge, 3. advocate, 4. later, teacher of eloquence, rhetorician».
} 
El vocablo latino por el que se traduce declamator ${ }^{24}$ remite a declamo, 'ejercitarse en oratoria' y a las declamationes, última etapa de la enseñanza retórica, y doctor ${ }^{25}$ a doceo, 'el que enseña'. Debemos mencionar que Alardo dedicó alguna atención a los términos declamare y declamationes de los que dice: Hoc ergo erat declamare in scholis exercitationis causa dicere. Itaque declamatio non aliud est quam oratio scholastica ad similitudinem forensis orationis dicta (Alardus $1539^{1}, \mathrm{p} .1$ ). Cada término enfatiza cierto aspecto, el préstamo sophista remite a la pericia y declamator y doctor se vinculan con la enseñanza y, específicamente, declamator, con la enseñanza de la retórica y, concretamente, con los ejercicios escolares de oratoria.

Ahora bien, al maestro de retórica, en latín, se le puede llamar también orator. Así, Prisciano cuando, hablando de la fábula, dice que los maestros de retórica suelen utilizar este ejercicio en el primer lugar por su valor ético, emplea el vocablo orator $^{26}$, que se encuentra algo después con el significado de orador, cuando señala que los oradores entre los ejemplos incluyen las fábulas ${ }^{27}$. Es evidente que el mismo vocablo se usa con dos acepciones distintas ${ }^{28}$.

Aunque Alardo y Mal Lara tratan de las diferencias existentes entre sophista, rhetor y orator y las conocen, no son sistemáticos en su uso de los términos. Alardo en $A$ rhetoribus est etiam usurpata ${ }^{29}$ señala que los primeros en usar la fábula fueron los poetas que se sirven de ella para proporcionar placer y que los rhetores la usan para advertir y como ejemplos de estos recurre a Demóstenes y Menenio Agripa. Es decir, emplea rhetores por oradores, no por maestros, aunque use para designarlos ese término. Mal Lara, en cambio, en el comentario general a la fábula, a la pregunta ${ }^{30}$ Cur opportunus a fabulis ad rhetoricem est uisus ingressus? (Mal Lara 1567, f.8r) responde que pasa a los oratores, porque, por su claridad de expresión, piensan que

\footnotetext{
${ }^{24}$ Según el diccionario de Gaffiot (1934) declamator es «déclamateur, celui qui s'exerce à la parole» y declamo es «exposer qqch dans un exercice préparatoire, dans une déclamation». Para Lewis-Short (1879), declamator es «one who practises set speaking, a rhetorician, declaimer (diff. from orator, a practical speaker)» y declamo es «I.a to exercise one's self in rhetorical delivery, to practise speaking, to declaim». Tanto Gaffiot como Lewis-Short recogen ejemplos de declamator en Cicerón y en Quintiliano con esta acepción.

${ }^{25}$ Para Gaffiot doctor es «maître, celui qui enseigne» y para Lewis-Short «I.a teacher, instructor». También recogen ejemplos de Cicerón y Quintiliano.

${ }^{26}$ Primam tradere pueris solent oratores quia animos eorum adhuc molles ad meliores facile uias instituunt uitae (Keil-Hertz 1981, p.430; Passalacqua 1987, 0033).

27 Sciendum quod eam oratores inter exempla solent fabulis uti (Keil - Hertz, 1981, 431; Passalacqua, 1987, 0034).

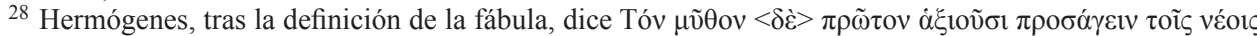
sin sujeto y simplemente con el verbo en plural, mientras que Prisciano emplea oratores: ideo autem hanc

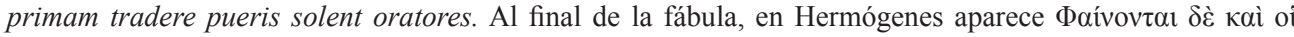

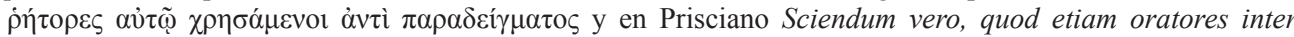

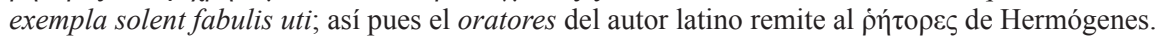

29 Agrícola comienza su traducción de la fábula de este modo: Fabula initio poetarum fuit. Postea uero, quod erudiendis pueris apta erat, a rhetoribus est etiam usurpata (Alardus $1539^{1}, \mathrm{p} .1$ ).

${ }^{30}$ Según Mal Lara las preguntas que deben hacerse sobre la fábula son cinco: ¿de dónde han podido surgir? ¿Cuántos pueden ser sus tipos? ¿Por qué ha parecido oportuno incluir las fábulas en la retórica? ¿Cuál es su utilidad? ¿Cuál su tratamiento? (Mal Lara 1567, ff.8r-9v).
} 
tiene la mayor afinidad con la gramática y recurre a Quintiliano como autoridad ${ }^{31}$; evidentemente, está refiriéndose al maestro de retórica, no al orador, aunque emplea también el término orator por orador, cuando dice que Cicerón recomienda la fábula a los oradores ${ }^{32}$; es decir, siguiendo el ejemplo de Prisciano, emplea el término con las acepciones de maestro de retórica y de orador. Lorich no se ocupa de estos asuntos, pero en la edición de 1542, cuando comenta que de la fábula se sirven los oradores, además de los poetas, aunque en la traducción al latín aparece Fabula traxit a poetis originem qua rhetores etiam communiter utuntur, quod admonitionibus sit idonea et erudiendis imperitioribus apta (Lorichius 1542, f.1r.), como entrada al comentario hallamos la variante qua etiam oratores etc. (Lorichius 1542, f.3r), en lugar de qua rhetores etiam, si bien la expresión aparece corregida en ediciones posteriores como la de 1643, en la que se encuentra rhetores. Es muy significativo el uso de oratores en vez de rhetores.

¿Influye la elección de rhetor en el comentario? Obviamente, en Alardo y Lorich no influye. Ambos comentan el uso que de la fábula hacen los oradores, Alardo en la entrada $A$ rhetoribus y Lorich en qua etiam oratores etc., como ya hemos visto. Mal Lara, aunque no tiene ninguna entrada similar, a su papel en la oratoria se refiere en el comentario general al ejercicio, pues, al responder a la pregunta quis usus?, indica que la utilidad de la fábula es doble, atraer la benevolencia y confirmar una opinión ante oyentes poco instruidos, así como amonestar a los astutos y experimentados ${ }^{33}$; pero parece que ha entendido la expresión a rhetoribus est etiam usurpata de la traducción de Agrícola como uso en la retórica, no en la oratoria, pues, como evidencia la pregunta Cur opportunus a fabulis ad rhetoricem est uisus ingressus? que acabamos de ver comenta su introducción en la retórica y no, como sería esperable, su paso a la oratoria; por otro lado, además de la traducción de Aftonio no se puede desdeñar la influencia de Prisciano en este punto ( $c f$. nota 27).

\section{Mĩ $\theta 0 \varsigma$ / FABVLA}

Otro término que debemos comentar es el del nombre del ejercicio. Ya en griego existen diversos vocablos para designar la narración parenética cuyo propósito es instruir sobre algún principio ético o moral o de comportamiento, por lo general situado al final o al principio, y denominado moraleja; Hesíodo la llama aǐvos y Aris-

\footnotetext{
31 Tertio ea causa a poetis ad oratores fabula emanauit, quod claritate dictionis maximam cum grammaticam affinitatem habeat quam causam probamus ex Fabio li. 2, cap. 4, in hunc modum: 'Ac mihi opportunus maxime uidetur ingressus ab eo, cuius aliquid simile apud grammaticos puer didicerit'(Mal Lara 1567, ff.8v-9r).

${ }^{32}$ Cicero in Partitionibus fabulam commendat oratoribus, his uerbis: 'Fabula etiam nonnunquam et si sit incredibilis, tamen homines commouet'(Mal Lara 1567, f.9r).

${ }^{33}$ Quarto, fabulae usus est duplex aut ad conciliandam beneuolentiam excitata hilaritate aut ad alicuius sententiae confirmationem, cum apud indoctos habeatur oratio... Aut denique ad repraehensionem astutorum et callidorum hominum, ut saepe solet M. Cicero. (Mal Lara 1567, f.9r).
} 


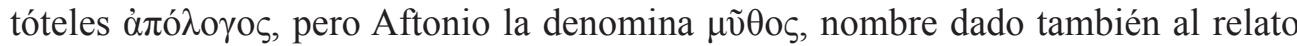
mítico.

En latín se traduce $\mu \tilde{v} \theta$ os por fabula ${ }^{34}$ lo que lleva también a un problema de ambigüedad, a la confusión entre mito ('narración maravillosa situada fuera del tiempo histórico y protagonizada por personajes de carácter divino o heroico') y este tipo de narración parenética. Claramente ello se refleja en los comentaristas. Estos en la teoría hablan de la fábula como un tipo específico de relato, se refieren a la posición de la moraleja y remiten a fábulas de Hesíodo y de Horacio, pero, cuando aportan ejemplos, podemos ver que se produce confusión. Así, Alardo, en su comentario a A rhetoribus est etiam usurpata, proporciona ejemplos de cómo los oradores usan la fábula para advertir, dice que así lo hicieron Demóstenes y, según recoge Tito Livio, Menenio Agripa, pero, además, añade que Cicerón utilizó la fábula en discursos como Pro Sexto Roscio ${ }^{35}$ y Pro Milone en el que se discute si se puede matar ${ }^{36}$ conforme a derecho ${ }^{37}$, aunque lo que encontramos en estos discursos no son fábulas, sino un mito, el de Orestes y Clitemnestra. Además, remite a De inuentione, al 'capítulo de la narración' sin más especificaciones, probablemente se refiera al capítulo 27 del libro primero, en donde Cicerón se ocupa de los tipos de narración: fabulam, historiam, argumentum, pero no dedica ningún apartado a la fábula esópica ${ }^{38}$. La única coincidencia entre la fábula y el relato mítico es que ambos comparten su denominación, fabula. Algo similar aparece en Mal Lara, que, en el comentario general al ejercicio, después de tratar de la utilidad de la fábula, por un lado, recuerda la fábula de Menenio Agripa y la de Horacio de la zorra y el león enfermo, y, por otro, dice que Demóstenes ${ }^{39}$ recurrió a la fábula de Minerva ${ }^{40}$, cuando vio que había perdido la atención del pueblo; es decir, como había hecho Alardo, de nuevo, vemos ejemplos de fábulas y de mito como si fueran el mismo tipo de relato .

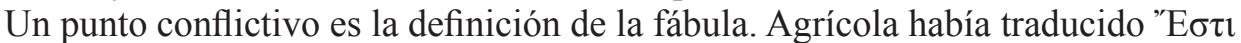

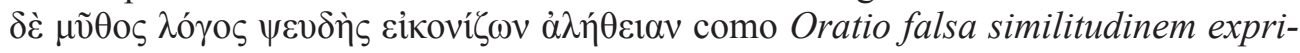

\footnotetext{
${ }^{34}$ Otras denominaciones para las fábulas son fabellas, logos Aesopeos, apologationes, como recoge Quintiliano en Institutio oratoria, 5.11.20, y apologos que vemos en Plauto en Stichus, 538, 541, 544, 570.

${ }^{35}$ Alardo no da la cita completa, sino el inicio: Videtisne quos nobis poetae etc. (Alardus $1539^{1}$, p.2) La cita completa es: Videtisne quos nobis poetae tradiderunt patris ulciscendi causa supplicium de matre sumpsisse, cum praesertim deorum immortalium iussis atque oraculis id fecisse dicantur, tamen ut eos agitent Furiae neque consistere umquam patiantur, quod ne pii quidem sine scelere esse potuerunt? (CIC. S. Rosc.66).

${ }^{36}$ Idem pro Milone, in ea quaestione disputat an possit ullus ab altero occidi iure (Alardus 1539', p.2).

${ }^{37} \mathrm{El}$ texto al que alude Alardo debe ser este: Itaque hoc, iudices, non sine causa etiam fictis fabulis doctissimi homines memoriae prodiderunt, eum qui patris ulciscendi causa matrem necauisset uariatis hominum sententiis non solum diuina sed etiam sapientissimae deae sententia liberatum (CIC. Mil.8).

${ }^{38} \mathrm{Al}$ apólogo se refiere de pasada, cuando señala que es útil recurrir a él o al mito cuando el auditorio está cansado. Sin auditoris studium defatigatio abalienauit a causa, te breuius, quam paratus fueris, esse dicturum commodum est polliceri; non imitaturum aduersarium. sin res dabit, non inutile est ab aliqua re noua aut ridicula incipere aut ex tempore quae nata sit, quod genus strepitu, acclamatione; aut iam parata, quae uel apologum uel fabulam uel aliquam contineat inrisionem (CIC.Inu.1.25).

39 Demosthenes, cum populum minus attentam intelligeret quodam Mineruae apologo (Mal Lara 1567, f.9r)

${ }^{40}$ Debe de referirse al discurso De falsa legatione (Or.19.255) en el que Demóstenes pide que se lean los versos de Solón en los que se presenta a Palas Atenea como protectora de la ciudad.
} 
mens ueritatis (Alardus $1539^{1}$, p.1) y la versión utilizada por Lorich como Est autem fabula, sermo falsus, ueritatem effingens (Lorichius 1542, f.1r). Los comentaristas, ante la difícil conciliación de falsus y ueritas, en sus comentarios, se detienen en la definición o nos dan una propia o, incluso, hacen ambas cosas. Alardo la define como fabula est sermo fictus delectationis utilitatisque gratia imaginem quandam morum exhibens $^{41}\left(1539^{1}\right.$, p.2), sustituyendo falsus por fictus y ueritas por mores, con lo que evita la paradójica mezcla de lo falso y la verdad y hace hincapié en que es un retrato de las costumbres. Lorich no la define, pero comenta que en ella puede manifestarse la verdad y que, aunque el relato no es verdadero, lo es su significado: quamuis $f a-$ bulosa sint argumenta et nullam ueritatis uim continere uideantur tamen rationem habent ut iuxta eam ueritas possit manifestari ficta quidem narratione sed ueraci significatione (Lorichius 1542, f.4r). Mal Lara critica el uso de falsa, que considera muy poco acertado, y señala, recurriendo a las definiciones de Donato en su comentario al Eunuchus de Terencio ${ }^{42}$, que debería haberse dicho ficta, pero añade que puede justificarse la elección de Agrícola, ya que $\psi \varepsilon v \delta$ $_{\varsigma}$ puede significar mendax; el humanista hispalense proporciona, también, una definición propia: Fabula igitur est oratio quae rem nec ueram nec uerisimilem continet (Mal Lara 1567, f.10v). No dejan de resultar contradictorias sus palabras pues, según Donato, al que recurre como autoridad, fictum es lo que no es verdadero, pero es verosímil; por tanto, fictum no se adapta a su definición. En realidad, Mal Lara ha definido la narración mítica, no el apólogo, y lo ha hecho de acuerdo con la preceptiva latina ${ }^{43}$; no obstante, para no despojar completamente a la fábula de verdad y verosimilitud añade seguidamente Quod ad materiam spectat, non ad tractationem (Mal Lara 1567, f.10v).

No es cuestión irrelevante la traducción de un término, ya que tiene consecuencias: puede dar lugar a ambigüedades, si se usa un mismo vocablo con dos acepciones distintas, como sucede al utilizar fabula para la narración mítica y para la parenética, y puede llegar a influir sobre el entendimiento y la comprensión del concepto. Como hemos visto, Alardo y Mal Lara proporcionan ejemplos de mitos en lugar de ejemplos de fábula y Mal Lara llega a dar la definición de narración mítica. La elección de $f a$ bula es deliberada, pues existían términos que no llevaban a confusión, como fabella, apologos o apologationes, utilizados por Quintiliano (cf. nota 35).

\footnotetext{
${ }^{41}$ Prisciano la había definido como Oratio ficta uerisimile dispositione imaginem exhibens ueritatis (KeilHertz 1981, p.430; Passalacqua 1987, 0033).

${ }^{42}$ La cita de Donato que reproduce Mal Lara es esta: Falsum est quo tegitur id quod factum est, uanum quod fieri non potest, fictum quod non est factum et fieri potuit. Vel falsum est fictum mendacium simile ueritati, uanum nec possibile nec uerissimile. Falsum loqui mendacis est, fictum callidi, uanum stulti. Falsum loqui turpe, est fictum uirtutis, uanum uercordiae. Falsis decipimur, fictis delectamur, uana contemnimus. Falsum loqui mendacis est, fictum callidi, uanum stulti. Falsum loqui turpe, est fictum uirtutis, uanum uercordiae. Falsis decipimur, fictis delectamur, uana contemnimus (DON.TER.Eun. 104). Donato incluye también fictum totum sine uero sed uerissimile omitido por Mal Lara.

${ }^{43}$ Fabula est, quae neque ueras neque ueri similes continet res, ut eae sunt, quae tragoedis traditae sunt (Rhet. Her. 1.13); fabula est, in qua nec uerae nec ueri similes res continentur (CIC.Inu.27); Accepimus species, fabulam, quae uersatur in tragoediis atque carminibus non a ueritate modo sed etiam a forma ueritatis remota (QVINT.Inst.2.4.2).
} 


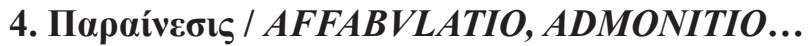

No podemos dejar de referirnos a la traducción de $\pi \alpha \rho \alpha i ́ v \varepsilon \sigma 1 \varsigma^{44}$-que aparece en dos ocasiones en la fábula- y a los comentarios al respecto.

En primer lugar, hay que señalar que los traductores no vierten el término al latín

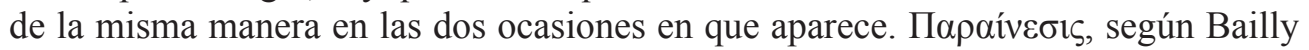
significa: «1. exhortation, encouragement, 2. avis, conseil»; para Lidell-Scott-Jones tiene los siguientes significados: «exhortation, address, advice or counsel». Agrícola traduce el texto en el que Aftonio señala que la fábula, iniciada con los poetas, la em-

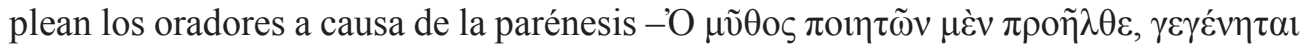

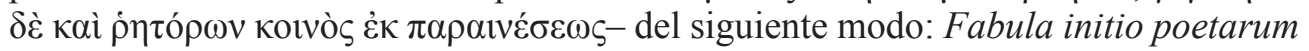
fuit. Postea uero, quod erudiendis pueris apta erat, a rhetoribus est etiam usurpata (Alardus $1539^{1}$, p.1); y la versión partim ... partim, usada por Lorich, de este otro: Fabula traxit a poetis originem, qua rhetores etiam communiter utuntur, quod admonitionibus sit idonea et erudiendis imperitioribus apta (f.1r). Es decir, Agrícola traduce $\dot{\varepsilon} \kappa \pi \alpha \rho \alpha \imath \varepsilon \dot{\sigma} \sigma \omega \varsigma$ mediante la perífrasis quod erudiendis pueris apta erat focalizando su atención en la enseñanza y, concretamente, en la enseñanza de los niños. La versión partim ... partim utilizada por Lorich se sirve también de una perífrasis, incluso más amplia, quod admonitionibus sit idonea et erudiendis imperitioribus apta que recoge la noción de enseñanza, presente en Agrícola, pero no dirigida a los niños, sino a los poco cultivados y añade la idea de admonición, recuerdo o aviso ${ }^{45}$. En cuanto a los comentarios, en Lorich no hay escolios al respecto mientras que tanto Alardo como Mal Lara tienen una entrada para Erudiendis pueris. Alardo se limita a decir que casi lo mismo se encuentra en Quintiliano 1.15, aunque el libro primero de la Institutio oratoria tiene sólo 12 capítulos. Mal Lara comenta su utilidad en la enseñanza por la facilidad de su expresión y porque informa sobre costumbres; dice que parenesis significa 'instrucción', 'corrección', 'reprensión', 'prescripción', 'reproche', 'doctrina' y remite a Erasmo ${ }^{46}$, a De conscribendis epistolis ${ }^{47}$ para obtener

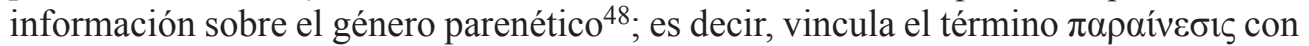
la enseñanza y la reprimenda, y no con la exhortación y la recomendación.

\footnotetext{
${ }^{44}$ Solo encontramos el término en Aftonio ya que Teón no utiliza un término específico para la moraleja, mientras que Hermógenes empleará una perífrasis (Patillon 2008, p.113, n. 6).

${ }^{45}$ Según el Dictionnaire Latin-Français de F. Gaffiot, Admonitio significa «Action de faire souvenir, rappel; action de faire remarquer (constater); avertissement». No podemos olvidar que admoneo es también 'admonester'. Para A Latin Dictionary de Ch. T. Lewis y Ch. Short significa «A reminding, recalling to mind, suggestion» y también «A friendly, mild admonition», e incluso «correction, chastisement».

${ }^{46}$ Tum propter dictionis facilitatem, tum etiam propter morum informationem, quod paraenesis sonat, ut instructio, correctio, reprehensio, praeceptio, obiurgatio, doctrina. De paerenetico genere, lege Erasmum in De conscribendis epistolis (Mal Lara 1567, f.10v.)

${ }^{47}$ Erasmo en De conscribendis trata de la epistula exhortatoria, en el inicio menciona el género parenético (1971, p.324) y en el apartado De exemplis fabulosis (pp.336-340) se refiere a los apologos Aesopicos y recuerda la fábula de Menenio Agripa.

${ }^{48}$ También, como ya hemos dicho, define la fábula como una narración que contiene un tema que no es ni verdadero ni verosímil y añade que esto se refiere al contenido, pero no al tratamiento. Es decir, Mal Lara mezcla el relato mítico con el fabulístico.
} 
El término $\pi \alpha \rho \alpha i ́ v \varepsilon \sigma 1 \varsigma$ aparece una segunda vez para indicar el nombre que recibe

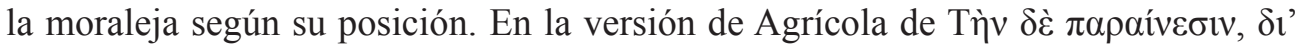

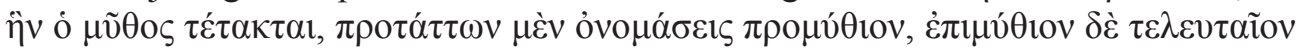

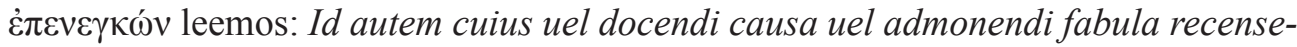
tur, si praeponas, $\pi \rho{ }^{\prime} v_{010 v}$, id est, (ut ita dixerim) praefabulare. Si subiicias fabulae, غ̇ंıv́์iov, id est, subfabulare appellatur (Alardus $1539^{1}$, p.1); en cambio, en la versión Partim ... partim encontramos: Quod si admonitionem cuius causa inuenta est, praeposueris, $\pi \rho \mu_{0} \theta 10 v, i d$ est, ut ita dixerim, praefabulare. Si uero postpo-

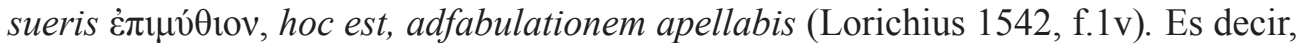
Agrícola traduce $\pi \alpha \rho \alpha i ́ v \varepsilon \sigma i s$ como id cuius uel docendi causa uel admonendi y la versión que utiliza Lorich como admonitionem, de modo que, frente a las traducciones anteriores (erudiendis pueris de Agrícola y admonitionibus sit idonea et erudiendis imperitioribus apta de partim ... partim), Agrícola añade a la idea de instrucción la de advertencia o admonición y la partim ... partim elimina la de instrucción.

En cuanto a los comentarios, Alardo tiene, de nuevo, una entrada para la parénesis, Id autem cuius uel docendi causa uel admonendi causa recensetur (15391 , p.4), $\mathrm{y}$, en su comentario, remite a Erasmo a los Adagios para conocer cómo se diferencia la paremia de formas afines, así como a Quintiliano 8.4. Además, en la entrada Est

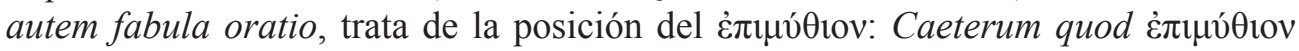
Graeci, Latinorum quidam affabulationem uocant, hoc est, apologi interpretationem initio ponas an in fine non magni refert $\left(1539^{1}\right.$, p.3). Lorich no tiene entrada para la

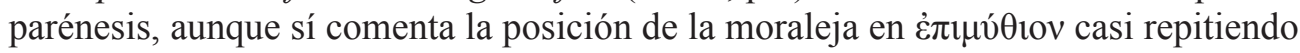
las palabras de Alardo: Caeterum quod غ̇ंuนvîıov, id est, apologi interpretationem appellant non admodum refert initio ponas an in fine (Lorichius 1542, f.7r). Ya Prisciano había denominado a la moraleja epimythion y affabulationem, aunque difiere en su postura respecto a la posición ya que sostiene que colocarla tras el relato es

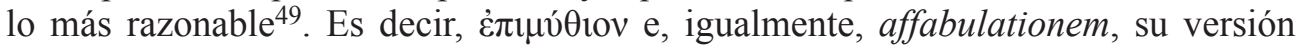
latina, son sinónimos de parénesis. Mal Lara, por su parte, no tiene ninguna entrada para la moraleja o su posición, pero en et sunt fabularum dice: si paraenesin, hoc est, admonitionem respicimus, propter quam fit fabula, si praeponas dicitur a loco, promythion, si post, epimythion (1567, f.11r); por otro lado, en el comentario general a la fábula dice Contrahimus fabulam cum simplicem et nudam narrationem proponimus sine ullo ornatu et in fine, epimythion, id est, subfabulare, aut fabulae inflexionem ad mores, uulgo adfabulatio dicitur, his uerbis fabula significat, alii morale uocant ${ }^{50}(1567, \mathrm{f} .9 \mathrm{v})$.

En resumen, para traducir $\pi \alpha \rho \alpha i ́ v \varepsilon \sigma 1 \zeta$, además de emplear los vocablos que aparecen en la traducción de Aftonio, Alardo recuerda que se la suele denominar

\footnotetext{
49 Dice Prisciano: ... quam epimythion uocant quod nos affabulationem possumus dicere a quibusdam etiam praeponitur, a plerisque rationabilius postrema ponitur (Keil-Hertz 1981, pp.430-431; Passalacqua 1987, 0034).

${ }^{50} \mathrm{El}$ Brocense en su breve comentario a la fábula denomina también morale a la moraleja: Si morale ponatur ante fabulam, non oportet in fabula narranda multum remorari.
} 
affabulationem y tanto él como Lorich se refieren a ella denominándola apologi interpretationem; en cambio, Mal Lara nos proporciona muchas variantes: además de admonitionem, la denomina paraenesin, fabulae inflexionem ad mores, morale $e^{51}$, epimythion y subfabulare.

El término griego $\pi \alpha \rho \alpha i ́ v \varepsilon \sigma ı \varsigma$ indica, primordialmente, 'exhortación, recomendación, consejo'. Los términos empleados en latín muestran otros aspectos. Quizás el vocablo latino que más similitudes presenta con $\pi \alpha \rho \alpha i ́ v \varepsilon \sigma 1 \zeta$ es admonitio, pero este término incluye la acepción de reprender además de acción de traer a la memoria y de advertir. Por otro lado, las traducciones que estamos considerando emplean otras formulaciones en las que se incluye la enseñanza (Agrícola, erudiendis pueris apta y docendi causa; la versión partim, partim: erudiendis imperitioribus). Los escoliastas emplean otras fórmulas que dan entrada a las costumbres (Mal Lara: fabulae inflexio ad mores y morale) o que especifican la función de la parénesis (Alardo y Lorich: interpretatio).

\section{CAMBIO DEL CONCEPTO DE LA FÁBULA}

La concepción que hoy se tiene del género debe mucho más a los latinos y a los humanistas que a los griegos. El francés toma los términos 'fable' y 'morale' del latín y el inglés, 'fable' y 'moral', de modo indirecto a través del francés; el español emplea 'fabula' y 'moraleja' con sufijo diminutivo. En cuanto al entendimiento del término, en francés significa:

II. Récit dont les épisodes, les héros, les circonstances sont imaginaires ou relèvent de la fiction. 1. Récit légendaire ou mythique relatif à l'histoire d'un peuple, d'une religion, d'une civilisation. L'histoire des origines de Rome est mêlée de beaucoup de fables. Cet épisode édifiant est une pure fable. Singulier collectif. Ce chroniqueur déguise la vérité sous la fable. Les traits qu'on prête à ce prince relèvent de la fable. Spécialt. Class. Récit relatif aux divinités du paganisme. Les fables de la mythologie grecque. Singulier collectif. La Fable, l'ensemble des récits de la mythologie antique. Les dieux, les héros de la Fable. Dictionnaire de la Fable.

2. Apologue, court récit en prose ou en vers par lequel on exprime une vérité générale, le plus souvent morale, sous le voile de la fiction. Les fables d'Ésope, de Phèdre, de La Fontaine, de Florian. "Le Chêne et le Roseau» est une fable célèbre. La fable du Loup et de l'Agneau. Le renard de la fable. La moralité ou la morale d'une fable, la leçon morale qu'elle fait apparaître et, par méton., la partie de la fable où cette leçon est explicitement formulée.

(Dictionnaire de l'Académie française).

En inglés, 'fable' se entiende como:

\footnotetext{
${ }^{51}$ Esta última denominación morale, que incide en las costumbres es la que ha triunfado en francés e inglés, así como en español, tras haber recibido un sufijo de diminutivo que da lugar a 'moraleja'.
} 
1. b. esp. A fictitious story relating to supernatural or extraordinary persons or incidents, and more or less current in popular belief; a myth or legend. (Now rare.) Also, legendary or mythical stories in general; mythological fiction.

2. A short story devised to convey some useful lesson; esp. one in which animals or inanimate things are the speakers or actors; an apologue. Now the most prominent sense.

(The Oxford English Dictionary OED).

En español, 'fábula' tiene, entre otras acepciones, las siguientes:

1. f. Breve relato ficticio, en prosa o verso, con intención didáctica frecuentemente manifestada en una moraleja final, y en el que pueden intervenir personas, animales y otros seres animados o inanimados.

2. f. Cada una de las ficciones de la mitología. La fábula de Psiquis y Cupido, de Prometeo, de las Danaides.

(RAE, Diccionario esencial de la lengua española).

Como podemos apreciar, se mantiene la ambigüedad existente en latín que ya hemos mencionado: narración mítica y apólogo.

En cuanto a la parénesis, en francés se dice morale, en inglés, moral, y en español, con un sufijo diminutivo, 'moraleja', es decir, triunfa el término latino que está vinculado con las costumbres.

Respecto al significado, en francés, morale tiene la acepción de:

3. Leçon morale, avertissement que l'on donne à quelqu'un quant à sa conduite. Faire de la morale ou faire la morale à quelqu'un, le réprimander, l'avertir d'avoir à s'amender. Par ext. La morale d'un ouvrage, la leçon morale qui s'en dégage, ou encore les quelques phrases de vers ou de prose qui la résument (on dit aussi Moralité). La morale d'une fable de La Fontaine. Expr. fam. La morale de l'histoire, la leçon qu'on tire d'un évènement, d'un fait.

(Dictionnaire de l'Académie française)

En ingles, moral, mantiene la misma acepción:

3. b. An exposition of the moral teaching or practical lesson contained in a literary work; that part of a work which expounds or contains the moral meaning.

(The Oxford English Dictionary OED).

En español, 'moraleja' se define como «Lección o enseñanza que se deduce de un cuento, fábula, ejemplo, anécdota, etc.» (RAE, Diccionario esencial de la lengua española).

Por tanto, puede verse cómo predomina el sentido de 'lección, enseñanza' en las tres lenguas. 


\section{CONCLUSIONES}

1. Para traducir los términos griegos, como hemos visto, se recurre, a veces, a préstamos como epimythion, sophista, rhetor, apologus, parenesis, otras, a calcos como subfabulare, orator; tampoco faltan las perífrasis como fabulae inflexio ad mores o apologi interpretatio ni la utilización de otros vocablos ya existentes en la lengua latina que no son calcos como doctor o declamator.

La elección no parece obedecer a la razón de evitar la ambigüedad, ya que rhetor y fabula perpetúan las existentes en griego. Hay intentos, aunque no llegan a triunfar plenamente, de utilizar orator para el orador y rhetor para el maestro de retórica. En cuanto a fabula, la lengua griega poseía también otros términos a los que podían

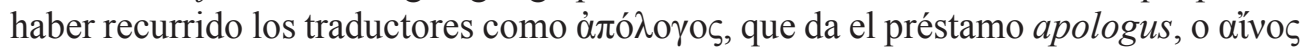
no usado en latín. Por otro lado, también existen otros procedimientos para evitar la ambigüedad, por ejemplo, con la adición del morfema de diminutivo se produce la desambiguación, fabula/fabella. Así pues, debemos pensar que la elección de un término obedece sólo a preferencias del traductor.

2. La existencia de un término acuñado no impide que se creen otros nuevos. Por ejemplo, Cicerón había usado para denominar al 'maestro de retórica', además de rhetor, doctor, pero en las traducciones de Aftonio encontramos sophista. Igualmente, en Prisciano aparecían los términos epimythion y affabulationem y, no obstante, Agrícola prefiere subfabulare. Además, los escoliastas emplean, con frecuencia, vocablos diferentes de los que se encuentran en las traducciones como inflexio ad mores; posiblemente ello se deba al deseo de mostrar originalidad.

3. Las traducciones por palabras existentes en la lengua meta dotan al término de nuevas acepciones. Sophista y rhetor con el significado de maestro de retórica, cuando se traducen como doctor o declamator, inciden en la enseñanza y en los ejercicios propios de la retórica y no en la habilidad o sabiduría ni en el simple hecho de hablar. Respecto a la parénesis que, en griego, tenía las acepciones de aviso y recomendación, vemos que, en latín, se priman los aspectos de enseñanza y de reprimenda, de modo que encontramos admonitionibus idonea et erudiendis imperitioribus apta y instructio, correctio, reprehensio... doctrina.

4. Los escoliastas, a veces, utilizan denominaciones que aclaran el concepto, así, Alardo y Lorich denominan a la parénesis interpretatio fabulae y Mal Lara fabulae inflexio ad mores y morale.

5. La traducción influye en el entendimiento del concepto y en el comentario, así sucede con rhetor y fabula que, según hemos visto, los escoliastas entienden, en ocasiones, como maestro de retórica y como narración mítica.

6. Por otro lado, la traducción tiene una doble vertiente, pues no solo influye en el entendimiento del concepto, sino que también responde a la concepción de la realidad a la que se refiere; así sucede con parénesis que se traduce, como ya hemos visto, por erudiendis pueris apta (Agrícola), o por interpretatio apologi (Alardo y Lorich) e inflexio ad mores (Mal Lara). 
7. La concepción que hoy se tiene del género debe mucho más a los latinos y a los humanistas que a los griegos.

\section{REFERENCIAS BIBLIOGRÁFICAS}

\subsection{TEXTOS}

Alardvs Aemstelredamvs (1532), Aphthonii Sopistae (sic) Progymnasmata, Rodolpho Agricolae Phrisio interprete... per Alardum Aemstelredamum, Coloniae apud Iohannem Soterem.

Alardvs Aemstelredamvs (1539), Rodolphi Agricolae Lucubrationes... per Alardum Aemstelredamum emendata, et additis scholiis illustrata, Coloniae, apud Joannem Gymnicum.

Alardvs Aemstelredamvs (1539²), Rodolphi Agricolae Phrisii De inuentione dialectica ... per Alardum Aemstelredamum accuratius enmendati ac additis annotationibus illustrati, Coloniae, Ioannes Gymnicus excudebat.

Alcazar, Bartholomaevs (1688), Aphthonii Sophistae Progymnasmata, publicada en De ratione dicendi, Matriti, ex typographia Joannis Garciae Infançonis.

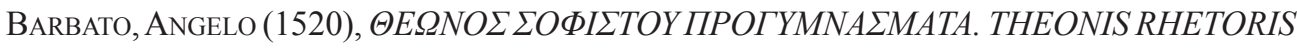
DE MODO DECLAMANDI LIBELLVS, Roma.

Bravo, Bartolomé (1589), Progymnasmata siue Praeexercitationes oratoriae cum singulis cuiusque progymnasmatis exemplaribus, Pamplona, T. Porral.

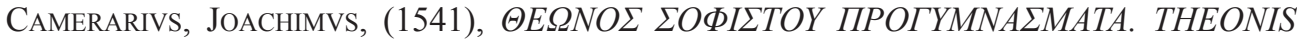
SOPHISTAE PRIMAE APVD RHETOREM EXERCITATIONES... et in sermone latino conversae, Basileae.

Catanaevs, Joannes Maria (1507), Aphthonii Progymnasmata, id est, Praexercitationes rhetorum et Luciani opusculum de componenda historia, Bononiae per Caligulam Bacilerium.

Erasmvs RotTedoramvs (1971), De conscribendis epistolis, J.C. Margolin (ed.), en Opera Omnia Desiderii Erasmi Roterodami, Ordinis Primi, Tomus Secundus, Amsterdam: North-Holland Publishing co.

Lorichivs, ReInHardvs (1542), Aphthonii Sophistae Progymnasmata, partim a Rodolpho Agricola, partim a Ioanne Maria Catanaeo... simul ac scholiis luculentis nouisque compluribus exemplis illustrata, per Reinhardum Lorichium Hadamarium, Marpurgi, in officina Christiani Egenolphi.

Lvllivs, Antonivs (1551), Progymnasmata Rhetorica, Basilea, Joannes Opporinus.

Mal Lara, JuAn De (1567), Ioannis Mallarae in Aphthonii Progymnasmata Scholia, Hispali, apud Escrivanum.

Manvtivs, Aldvs (1508-1509), Rhetores in hoc volumine habentur hi. Aphthonii Sophistae Progymnasmata. [...], Venetiis.

Mosellanvs, Petrvs (1530), De primis apud rhetorem exercitationibus praeceptiones, Cracovia, M. Scharffenbergk.

Nvnnesivs, Petrvs Johannes (1596), Progymnasmata, id est, praeludia quaedam oratoria ex 
progymnasmatis potissimum Aphthonii, Zaragoza, M. Eximino Sánchez (publicados por primera vez en 1578, Institutiones Rhetoricarum libri quinque, Barcelona).

Palmirenvs, Lavrentivs (1573), Segunda parte del Latino de repente, Valencia, P. de Huete. Pomey, Franciscvs (1664), Candidatus Rhetoricae, Monachii.

Sanctivs Brocensis, Franciscvs (1556), Aphthonii sophistae Progymnasmata Rhetorica. Rodolpho Agricola Phrisio interprete cum scholiis nuper additis per Franciscum Sanctium Brocensem Rhetorices professorem, Salmanticae, excudebat Andreas a Portonariis.

\subsection{DICCIONARIOS Y LÉXICOS}

ACADÉMIE FRANÇAISE, Dictionnaire de l'Académie française, neuvième Edition Version informatisée; (http://atilf.atilf.fr/academie9.htm, consultado: 03/06/2015).

Bailly, A. (1963), Dictionaire Grec-Française, Paris, Hachette, 1963.

Gaffiot, F. (1934), Dictionnaire Latin-Français, París.

Lewis, CH.T. - Short, CH. (1879), A Latin Dictionary, Oxford.

Liddell, H.G. - ScotT, R. - Jones, H.S., (LSJ) The Online Liddell-Scott-Jones Greek-English Lexicon (http://stephanus.tlg.uci.edu/lsj/\#eid=1\&context=lsj; consultado: 03/06/2015).

RAE, Diccionario esencial de la lengua española. Real Academia Española, http://lema.rae. es/drae/?val=f\%C3\%A1bula, consultado: 03/06/2015.

The Oxford English Dictionary (OED), (http://www.oed.com, consultado 03/06/2015).

\subsection{ARTÍCULOS Y MONOGRAFÍAS}

Arcos Pereira, T. (2015), «Los primeros niveles de la enseñanza de la retórica: los progymnasmata», en MAESTRE J.M. et alii (eds.), V Congreso Internacional de Humanismo y Pervivencia del Mundo Clásico. Homenaje al profesor Juan Gil (Alcañiz, 18-22 de octubre 2010) V,3, pp.1163-1190.

Arcos Pereira, T. - CuyÁs de Torres, M Ma E. (2007), «La enseñanza de la retórica en los Scholia in Aphthonii Progymnasmata de Juan de Mal Lara», Calamus Renascens 8, 25-34

Arcos Pereira, T. - Cuyás de Torres, Ma E. (2008), «Los Scholia de Juan de Mal Lara al progymnasma de la fábula de Aftonio», $C F C(L)$ 28.1, 115-137.

Arcos Pereira, T. - CuYÁs De Torres, Ma E. (2009), «La narración y el elogio en los Scholia in Aphthonii Progymnasmata de Juan de Mal Lara», en ArCos PereIRA, T. - Fernández López, J. - Moya del Baño, F. (eds.), Pectora mulcet. Estudios de Retórica y Oratoria Latina, Logroño, Instituto de Estudios Riojanos, II, pp.731-742, doi: 10.13140/2.1.2847.9683

Arcos Pereira, T. - CuyÁs de Torres, Ma E. (2010), «Los comentarios de los Progymnasmata de Aftonio de Francisco Escobar y Juan Mal Lara: estudio preliminar», en MAestre J.M. et alii (eds.), Humanismo y Pervivencia del Mundo Clásico IV. Homenaje a Antonio Prieto, Madrid - Alcañiz - Cádiz: CSIC, I, pp.651-662, doi: 10.13140/2.1.3039.1362. 
Arcos Pereira, T. - García de Paso Carrasco, Ma D. (en prensa), «El comentario de Alardo de Ámsterdam a los Progymnasmata de Aftonio traducidos al latín por Rodolfo Agrícola», Rhetorica.

Clark, D.L. (1952), «The Rise and Fall of Progymnasmata in Sixteenth Century Grammar Schools», Speech Monograph 19(4), 258-263.

CuyÁs DE TORRes, M ${ }^{\mathrm{a}}$ Elisa (2014), «Aftonio en el Renacimiento: el comentario al lugar común de Lorich», HumLov 63, 153-177.

Escobar Borrego, F.J. (2000), «Noticias inéditas sobre Fernando de Herrera y la Academia sevillana en el Hércules animoso de Juan de Mal Lara», Epos. Revista de Filología 16, 133-155

Escobar Borrego, F.J. (2004), «Nuevos datos sobre libros y lecturas de Juan de Mal Lara (A propósito de la Tabla de autores del Hércules animoso)», Criticón 90, 79-98.

EscobAr Borrego, F.J. (2012), «Juan de Mal Lara, maestro de la Escuela sevillana: contexto humanístico y apuntes biobibliográficos», en La Philosophía vulgar de Juan de Mal Lara, vecino de Sevilla, 1568. Edición facsímil a cargo de J.J. Labrador Herraiz y R.A. DiFranco, México, pp.47-101.

GraAF, B. DE (1958), Alardus Amstelredamus (1491-1554), Amsterdam, Menno Hertzberger.

Green, L.D. - Murphy, J.J. (2006), Renaissance Rhetoric Short-Title Catalogue 1460-1700, Hants - Burlington.

Johnson, F.R. (1942-43), «Two Renaissance Textbooks of Rhetoric: Aphthonius' Progymnasmata and Rainolde's A book called the Foundation of Rhetorike», Huntington Library Quarterly 6, 427-444.

KeIL, H. - Hertz, M. (1981), «Prisciano, Praexercitamina», en Grammatici Latini, vol. III, Hildesheim, Olms, pp.430-440 (Lipsiae, 1860).

Lorenzo, J. (2009), «El Rhetor y el Orator: enseñanza para la vida pública en Roma», en Arcos Pereira, T. - Fernández López, J. - Moya del Baño, F. (eds.), Pectora mulcet. Estudios de Retórica y Oratoria Latina, Logroño, Instituto de Estudios Riojanos, II, Logroño, Instituto de Estudios Riojanos, pp.83-102.

Margolin, M.J. (1979), «La rhétorique d'Aphthonius et son influence au XVI ${ }^{\mathrm{e}}$ siècle», en Chevalier, R. (ed.), Colloque sur la rhétorique, Paris, Les Belles Lettres, pp.239-271.

MERINO JÉREZ, L. (2002), «El Brocense y Juan de Mal Lara: una amistad inexplorada», RELat 2, 149-168.

Passalacqua, M. (1978), I codici di Prisciani, Roma, Edizioni di Storia e Letteratura.

Passalacqua, M. (1987), Prisciani Caesariensis opuscula: De figuris numerorum. De metris Terentii. Praeexercitamina, Roma, Edizioni di Storia e Letteratura.

Patillon, M. (2008), Anonyme, Préambule à la Rhétorique. Aphthonios, Progymnasmata. Pseudo-Hermogène, Progymnasmata, Paris, Les Belles Lettres.

Patillon, M. - Bolognesi, G. (1997), Aelius Theon, Progymnasmata, Paris, Les Belles Lettres (reimpr. 2002).

Pérez Custodio, V. (2003¹), Alfonso de Torres, Ejercicios de Retórica, Alcañiz-Madrid, Instituto de Estudios Humanísticos-Laberinto-CSIC.

Pérez Custodio, V. $\left(2003^{2}\right)$, «Los progymnasmata de la Antigüedad al Renacimiento», en Alfonso de Torres, Ejercicios de Retórica, Alcañiz-Madrid, Instituto de Estudios Alcañizanos, CSIC, pp.XLIV-LIX. 
Pérez Custodio, V. (2013), «Los progymnasmata de Teón en la España del XVI», Rhetorica $31.2,150-171$.

Rodríguez Herrera, G. - García de Paso Carrasco, Ma D. (2008), «Los poetas clásicos en los Comentarios de Reinhard Lorich y Juan de Mal Lara a los Progymnasmata de Aftonio: sententia, confirmatio, comparatio», HumLov 57, 149-166. 